\title{
Salinity tolerance of diapausing eggs of freshwater zooplankton
}

\author{
SARAH A. BAILEY,$*$ IAN C. DUGGAN,$*$ COLIN D.A. VAN OVERDIJK,$*$ THOMAS H. JOHENGEN,${ }^{+}$ \\ DAVID F. REID ${ }^{\ddagger}$ AND HUGH J. MACISAAC* \\ ${ }^{*}$ Great Lakes Institute for Environmental Research, University of Windsor, Windsor, Ontario, Canada \\ ${ }^{+}$Cooperative Institute for Limnology and Ecosystems Research, University of Michigan, Ann Arbor, MI, U.S.A. \\ ${ }^{\ddagger}$ National Oceanic and Atmospheric Administration, Great Lakes Environmental Research Laboratory, Ann Arbor, MI, U.S.A.
}

\section{SUMMARY}

1. Many freshwater zooplankton produce diapausing eggs capable of withstanding periods of adverse environmental conditions, such as anoxia, drought and extreme temperature. These eggs may also allow oligostenohaline species to survive increased salinity during periods of tidal flux or evaporation, and here we test the ability of diapause eggs to withstand such conditions.

2. Salinity tolerance may also enable organisms to invade new environments. The increased rate of introduction of non-indigenous species to the Laurentian Great Lakes since 1989, when ballast water exchange regulations (to replace fresh/brackish water at sea with full seawater) were first implemented for transoceanic vessels, has stimulated studies that explore mechanisms of introduction, other than of active animals, in ballast water. One hypothesis proposes that freshwater organisms transported in ballast tanks as diapausing eggs may be partially responsible for the increased rate of species introduction, as these eggs may tolerate a wide array of adverse environmental conditions, including exposure to saline water.

3. We collected ballast sediments from transoceanic vessels entering the Great Lakes, isolated diapausing eggs of three species (Bosmina liederi, Daphnia longiremis and Brachionus calyciflorus), and measured the effect of salinity on hatching rate. In general, exposure to salinity significantly reduced the hatching rate of diapausing eggs. However, as nonindigenous species can establish from a small founding population, it is unclear whether salinity exposure will be effective as a management tool.

Keywords: ballast water exchange, biological invasion, hatching rates, resting eggs, salinity tolerance

\section{Introduction}

The introduction of non-indigenous species is a potent agent of biodiversity change, particularly for lake ecosystems (Sala et al., 2000) and measures are urgently needed to identify and eliminate the vectors that transport them. Ballast water is recognised as the single most important vector for species introduction to aquatic habitats. Approximately 10 billion tonnes of

Correspondence: Sarah A. Bailey, Great Lakes Institute for Environmental Research, University of Windsor, Windsor, Ontario, N9B 3P4, Canada. E-mail: sarahbailey@canada.com ballast water (and its associated biota) are transferred annually between global ports, providing the primary means of transport and introduction of non-indigenous aquatic biota to ecosystems, including bacteria, dinoflagellates, phytoplankton, zooplankton and fish (Rigby, Hallegraeff \& Sutton, 1999; Ruiz et al., 2000). Transoceanic shipping accounts for $77 \%$ of the species introduced to the Laurentian Great Lakes since 1970 (Ricciardi, 2001). To reduce this threat, voluntary regulations were enacted in 1989, and mandated in 1993, that effectively require inbound vessels to exchange fresh or brackish ballast water with openocean saltwater if that water is to be discharged in the 
Great Lakes (United States Coast Guard, 1993). Despite these regulations, the rate at which new species have been recorded in the Great Lakes tripled between 1989 and 1999 compared with the preceding 40 years (Grigorovich et al., 2003). Increased sampling effort and time lags between establishment and discovery of non-indigenous species may partially account for this pattern (Costello \& Solow, 2003; Grigorovich et al., 2003), although modelling exercises indicated that ballast water exchange offers only incomplete protection and is least successful for species with benthic or dormant stages contained within ballast sediments (MacIsaac, Robbins \& Lewis, 2002). Alternatively, the recent surge in non-indigenous species may be because of the presence of live or dormant organisms contained in the residual ballast of ships declaring 'no ballast on board', which are exempt from the regulations (MacIsaac et al., 2002; Bailey et al., 2003). These vessels carry tonnes of residual sediment and ballast water, and dominate trade inbound to the Great Lakes (Colautti et al., 2003).

Many freshwater zooplankton, including copepods, cladocerans and rotifers, produce diapausing or 'resting' eggs during annual population cycles. These dormant stages probably evolved as an adaptation to periods of adverse environmental conditions, including anoxia, drought and extremely low or high temperature (Gilbert, 1974; Hairston, 1996; Hairston \& Cáceres, 1996; Williams, 1998). These eggs could also provide temporal escape from unfavourable salinity, facilitating the intercontinental transfer of freshwater species in sediments of ballast tanks, even those subjected to ballast water exchange. Some of the species recently recorded in the Great Lakes are euryhaline endemics of the Ponto-Caspian region of southeast Europe, which may have been transported as resting stages in ballast water and/or sediments (Ricciardi \& MacIsaac, 2000; Reid \& Orlova, 2002). While the salinity tolerance of some juvenile and adult freshwater cladocerans and rotifers has been examined (e.g. Miracle \& Serra, 1989; Teschner, 1995; Hall \& Burns, 2002), very little is known of the salinity tolerance of the diapausing eggs of freshwater taxa. Consequently, it is difficult to infer whether invertebrates capable of producing diapausing eggs could circumvent the salinity 'filter' imposed on potential Great Lakes invaders by ballast water exchange.
In this study, we examine the effect of salinity on the hatching rate of diapausing eggs of the cladocerans Bosmina liederi De Melo \& Hebert and Daphnia longiremis Sars, and the rotifer Brachionus calyciflorus Pallas, common inhabitants of ballast sediments of transoceanic vessels entering the Great Lakes. While these three species are native to the Great Lakes, their presence in residual ballast sediments suggests that they are representative of the types of organisms that pose a potential risk of invasion. Bailey et al. (2003) tested the viability of diapausing eggs recovered from ballast sediments and noted a tendency for reduced viability with high pore water salinity, although this relationship was not tested directly. Here, we test the hypothesis that diapausing eggs of freshwater zooplankton will be destroyed by exposure to saline water.

\section{Methods}

\section{Sample collection}

Residual sediments were collected from five transoceanic vessels entering the Great Lakes in 'no ballast on board' status in December 2000, May, August and December 2001, and in June 2002. Ships were sampled at the ports of Hamilton, Thorold and Toronto, Ontario, Canada, and Cleveland, OH, U.S.A. Residual sediment was collected from at least one ballast tank per ship, with additional tanks sampled depending upon availability and the ease and safety of access. Sediments were collected along longitudinal shell frames that trapped sediment in areas away from drainage flows. Approximately $4 \mathrm{~kg}$ of sediment (in total) were collected from at least five areas within each tank and placed in a single container. These composite samples were stored in the dark at $4{ }^{\circ} \mathrm{C}$ until experimentation. The salinity of residual sediment pore water, separated from sediment by centrifugation at approximately $3300 \mathrm{~g}$ (approximately $32360 \mathrm{~m} \mathrm{~s}^{-2}$ ) for $15 \mathrm{~min}$, was measured using an optical refractometer (F. Dobbs, Old Dominion University, Norfolk, VA, U.S.A.).

\section{Egg density counts}

After thorough mixing, four $40-\mathrm{g}$ subsamples (wet weight) were taken from each sample and preserved in $95 \%$ ethanol. Subsamples were each washed 
288 S.A. Bailey et al.

through a $45 \mu \mathrm{m}$ sieve to remove fine sediment. Diapausing eggs were subsequently separated from the coarse sediment using the colloidal silica Ludox ${ }^{\circledR}$ HS 40 (Burgess, 2001) and counted under a dissecting microscope.

\section{Hatching experiments}

Sediments were stored in plastic containers in the dark at $4{ }^{\circ} \mathrm{C}$ for at least 4 weeks to allow a refractory period before hatching experiments commenced (see Grice \& Marcus, 1981; Schwartz \& Hebert, 1987). After this time, diapausing eggs were removed from sediment using a sugar flotation method (Bailey et al., 2003). Briefly, sediment was processed through a $45 \mu \mathrm{m}$ sieve and washed into centrifuge tubes using a $1: 1(\mathrm{w}: \mathrm{v})$ mixture of sucrose and water. After centrifugation (5 $\mathrm{min}$ at approximately $\sim 27 \mathrm{~g}$ ) the supernatant was decanted and rinsed thoroughly with water through $45 \mu \mathrm{m}$ mesh before being transferred to a counting dish. Diapausing eggs were immediately recovered from the supernatant and sorted by size and gross morphology under a dissecting microscope, selecting only fully intact, apparently healthy eggs. A single, replicated experiment was conducted on the most abundant egg type (Brachionus or Daphnia species) for each of five tanks. For sediment from ship 1, in which Brachionus budapestinensis Daday eggs dominated (see Table 1), experiments were attempted using $B$. budapestinensis, but were abandoned owing to loss of eggs over time because of their extremely small size. Experiments were therefore conducted on a subdominant species, B. liederi. All other eggs were incubated at $0 \%$ (parts per thousand salinity) for identification purposes only. Occasionally, two or three species hatched during a single trial (see Table 1). These secondary species always contributed $<1 \%$ of the total number of hatchlings. In total, 11 species hatched, although only three were used in the replicated experiments. Four trials were conducted with the rotifer B. calyciflorus and one trial each for the cladocerans $D$. longiremis and B. liederi.

Eggs used in the experiments were separated into 20 replicates of 20 eggs each, and placed into vials containing $15 \mathrm{~mL}$ of sterile medium $(0,8,16$, or $32 \%$ ) representing incremental efficiencies of ballast exchange. Five replicates were placed into each

\begin{tabular}{|c|c|c|c|c|}
\hline Ship & $\begin{array}{l}\text { No. of } \\
\text { replicates }\end{array}$ & Species & $\begin{array}{l}\text { No. eggs } \\
\text { per } 40 \mathrm{~g}\end{array}$ & $\begin{array}{l}\text { Pore water } \\
\text { salinity }(\%)\end{array}$ \\
\hline \multirow[t]{5}{*}{$1(\mathrm{FP})$} & $\mathrm{N} / \mathrm{A}$ & Brachionus budapestinensis & 92 & 2 \\
\hline & 5 & Bosmina liederi & 56 & \\
\hline & $\mathrm{N} / \mathrm{A}$ & Brachionus calyciflorus & 52 & \\
\hline & $\mathrm{N} / \mathrm{A}$ & Daphnia longiremis & 6.3 & \\
\hline & $\mathrm{N} / \mathrm{A}$ & Daphnia ambigua Scourfield* & & \\
\hline \multirow[t]{2}{*}{$2(\mathrm{DB})$} & 5 & Daphnia longiremis & 391 & 10 \\
\hline & $\mathrm{N} / \mathrm{A}$ & Daphnia ambigua* & & \\
\hline \multirow[t]{5}{*}{$3(\mathrm{DB})$} & 5 & Brachionus calyciflorus & 100 & 35 \\
\hline & $\mathrm{N} / \mathrm{A}$ & $\begin{array}{l}\text { Brachionus quadridentatus } \\
\text { f. rhenanus (Lauterborn)* }\end{array}$ & & \\
\hline & $\mathrm{N} / \mathrm{A}$ & Brachionus urceolaris Müller* & & \\
\hline & $\mathrm{N} / \mathrm{A}$ & Brachionus budapestinensis & 56.5 & \\
\hline & $\mathrm{N} / \mathrm{A}$ & Brachionus angularis Gosse* & & \\
\hline \multirow[t]{3}{*}{$4(\mathrm{DB})$} & 5 & Brachionus calyciflorus & 57.8 & 4 \\
\hline & $\mathrm{N} / \mathrm{A}$ & Daphnia magna Straus & 1.5 & \\
\hline & $\mathrm{N} / \mathrm{A}$ & Diaphanosoma sp. & $<1$ & \\
\hline $4(\mathrm{FP})$ & 5 & Brachionus calyciflorus & 119.5 & 20 \\
\hline \multirow[t]{2}{*}{5 (DB) } & 5 & Brachionus calyciflorus & 187.8 & 10 \\
\hline & $\mathrm{N} / \mathrm{A}$ & Asplanchna brightwelli Gosse & 1.5 & \\
\hline
\end{tabular}

Table 1 List of species hatched from ballast sediments through quantitative and qualitative hatching studies

Species with N/A replicates were not used during experimentation, and were hatched only for identification purposes. Ship tanks are identified by type: FP, forepeak tank; DB, double-bottom tank.

*Denotes secondary species hatched from single morphological egg type listed immediately above. 
salinity treatment at $20{ }^{\circ} \mathrm{C}$ (photoperiod $16 \mathrm{~h}$ light : $8 \mathrm{~h}$ dark), resulting in an experimental design using 400 eggs per trial. The $0 \%$ treatment was considered a control to assess maximum viability for these freshwater species. Synthetic pond water (Hebert \& Crease, 1980) or diluted, filtered, natural seawater (collected from a vessel transiting the Great Lakes loaded with ocean water ballast, filtered through $0.2 \mu \mathrm{m}$ Whatman number 5 paper filter) were used as hatching media. Vials were checked for emergence every $24 \mathrm{~h}$ for 10 days, with all hatched individuals removed daily. Media were refreshed on day 5 . On day 10 all remaining eggs were transferred to synthetic freshwater media by pipette to examine hatching rates after salinity exposure. Again, the number of hatchlings was recorded daily. Negative controls containing only treatment media were kept in each treatment group to detect any introductions of organisms from the environment. We chose the 10 day hatching period after exposure for two reasons. First, previous experiments indicated that $96 \%$ of hatching occurs within the first 10 days of trials run for 20 or 30 days in the manner described above (Bailey et al., 2003; unpublished data). Secondly, the typical transit time of a 'no ballast on board' vessel carrying Great Lakes water within the lake system is $7-10$ days. If the uptake of Great Lakes water does induce diapausing eggs contained in ballast sediments to hatch (as suggested by Bailey et al., 2003), this is the period of greatest risk.

Variation in the cumulative proportion of diapausing eggs hatched between treatments was analysed using a one-way ANOVA with repeated measures using Systat 8.0 (SPSS, 1998; SPSS, Chicago, IL, U.S.A.). Tukey's multiple comparison test was performed on the total proportion of eggs hatched to determine the impact of salinity on hatching rate. As emergence was inhibited at higher salinities, analyses were conducted on the 10-day hatching segment for each treatment, depending on the timing of emergence (i.e. days $0-10$ for 0 and $8 \%$ treatments were compared with days 10-20 for 16 and $32 \%$; if no hatching occurred during days $0-10$ for the $8 \%$ treatment, then days 10-20 were used). Only days when hatching occurred in at least one of the replicates were analysed. The proportion of eggs hatched was normalised using an arcsine square root transformation before analysis.

\section{Results}

Hatching experiments were conducted on zooplankton diapausing eggs isolated from residual ballast sediment collected from six tanks on five vessels. Salinity of sediment pore water varied from 2 to $35 \%$ (Table 1). Diapausing egg densities of dominant taxa were high ( $>50$ eggs per 40 g sediment, Table 1 ). Eggs were induced to hatch in all experiments, with hatching rates ranging from 16 to $89 \%$ in the $0 \%$ treatment (Fig. 1). In each experiment the proportion hatching declined with increasing salinity. No organisms were recorded in the negative control vials. Brachionus calyciflorus generally began to hatch within $24 \mathrm{~h}$ of incubation at $0 \%$, while for the cladocerans $B$. liederi and D. longiremis emergence began at day 3 (Fig. 1). Development also began promptly in the $8 \%$ treatments, with B. calyciflorus hatching in three out of four trials by day 5 . In addition, development of eyestage embryos was recorded by day 5 in the $8 \%$ treatments for 50 and $90 \%$ of Daphnia and Bosmina eggs, respectively (see Fig. 2a). Apparently, these species could not tolerate emergence into brackish water, as development always stopped before emergence from eggs was complete. None of the eye-stage embryos recorded in $8 \%$ treatment continued development after the medium was replaced with $0 \%$ water on day 10. Conversely, no organisms hatched or completed significant development during the 10 days of exposure at either of the two higher salinities (i.e. 16 and $32 \%$, Fig. 2b,c), although some lipid accumulation was noted in the $16 \%$ o treatment. Rather, emergence occurred in these treatments only after brackish or saltwater media were exchanged for $0 \%$ water (Fig. 1). After exchange, hatching rates among experiments varied between $0-31$ and $0-78 \%$ for the 16 and $32 \%$ treatments, respectively. Bosmina liederi was the only species tested for which no hatching occurred after exposure to any of the salinity $(>0 \%$ ) treatments.

The difference in hatching rate between treatments was highly significant for all trials $(P<0.05$, ANOvA, Table 2). All trials exhibited divergence of hatching rates over time, as time $\times$ treatment interaction terms were significant $(P<0.0001$, ANOvA, Table 2$)$. The proportion of eggs hatched was higher in the $0 \%$ treatment for eggs recovered from ships 1-4 (Fig. 1a-e; $P<0.05$, Tukey post hoc test). The hatching rates of $B$. calyciflorus for the 0 and $32 \%$ treatments for ship 5 
(a)

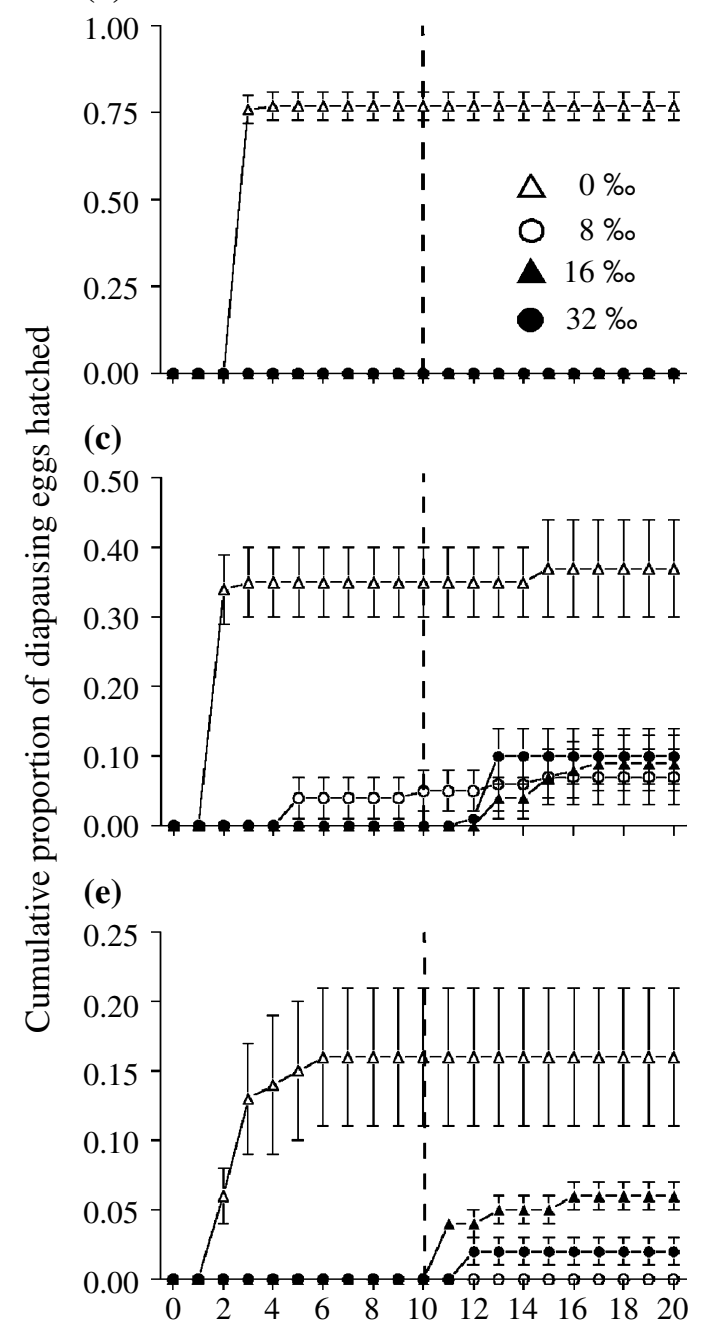

(b)

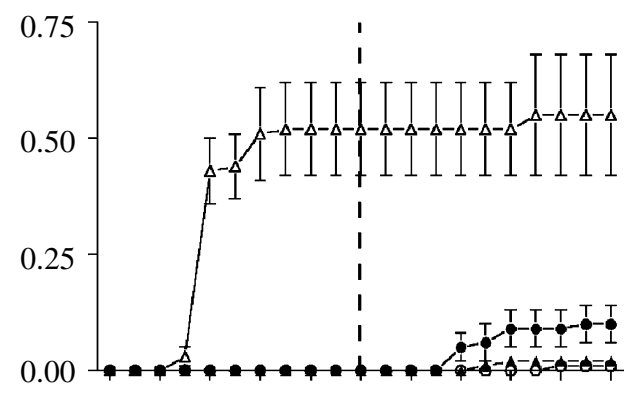

(d)

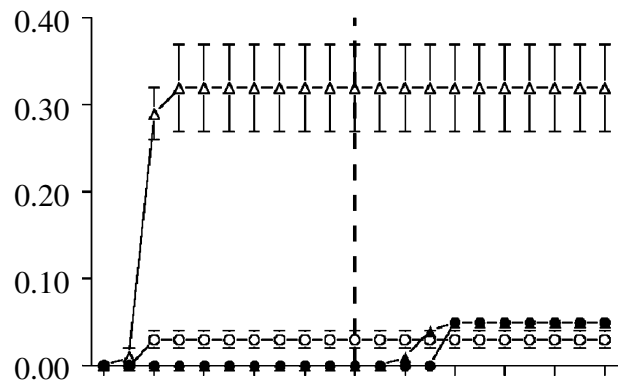

(f)

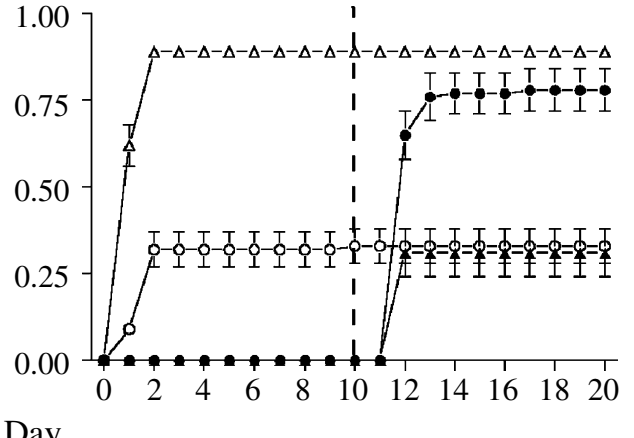

Fig. 1 Mean $( \pm S E)$ cumulative proportion of diapausing eggs hatched under salinity treatments, by species. (a) Bosmina liederi (ship 1), (b) Daphnia longiremis (ship 2), (c) Brachionus calyciflorus (ship 3), (d) B. calyciflorus (ship 4-DB), (e) B. calyciflorus (ship 4-FP) and (f) B. calyciflorus (ship 5). After 10 days (dotted vertical line) all unhatched eggs in each treatment group were transferred to $0 \%$ media. Note scale difference for each ordinate. Error bars $<0.03$ are hidden by graph symbol.

were significantly higher than for the other two treatments (Fig. 1f; $P<0.001$, Tukey post hoc test).

\section{Discussion}

To date, investigations of the salinity tolerance of freshwater zooplankton have been limited to measuring direct effects on growth and survival (e.g. Miracle \& Serra, 1989; Teschner, 1995; Hall \& Burns, 2002), or examining species richness and composition in waterbodies of varying salinity (Frey, 1993; Brain, Fourie \& Shiel, 1995). These approaches have not considered diapausing egg stages, probably resulting in an underestimate of the range of salinities a particular taxon can tolerate, particularly in instances where salinity varies temporally. In this study, we have demonstrated that the hatching rate of diapausing eggs is reduced by exposure to saline conditions. The ability of diapausing eggs to tolerate fluctuations in salinity may stem from an evolutionary history in temporary habitats, which generally fluctuate more in their physical and chemical environment than adjacent, permanent ones (Williams, 1998). 

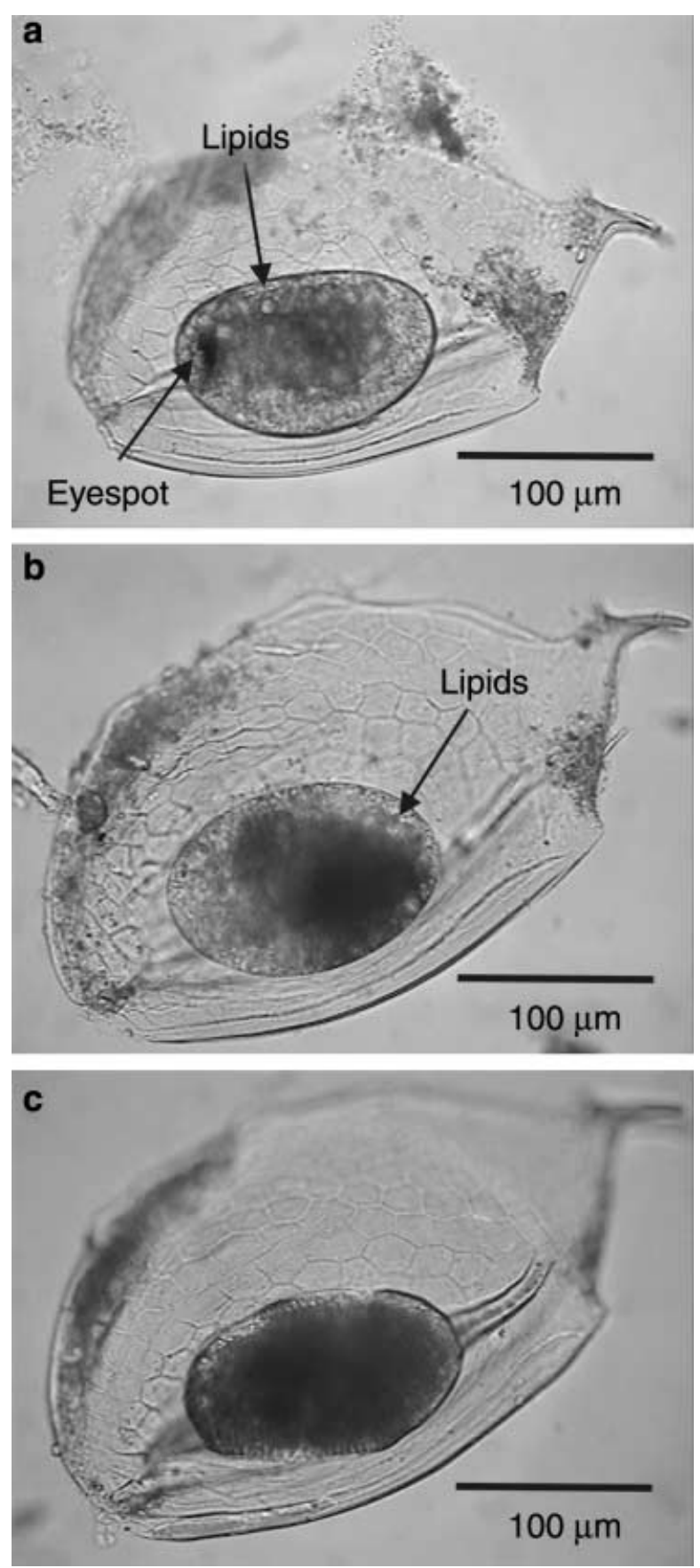

Fig. 2 Condition of diapausing eggs of Bosmina liederi after 10 days at each treatment. (a) 8\%, aborted eyed-embryo, (b) $16 \%$, little differentiation and (c) $32 \%$, no change. Scale bars $(100 \mu \mathrm{m})$ are included on each image.

Of the species examined here, diapausing eggs of $B$. liederi appear to exhibit the lowest salinity tolerance with no hatching after exposure to saltwater. Daphnia longiremis exhibited a modest degree of salinity tolerance, as a small proportion of diapausing eggs hatched following saltwater exposure. Brachionus calyciflorus demonstrated the widest tolerance, with up to $78 \%$ eggs hatching after saltwater exposure. Interestingly, B. calyciflorus also displayed a wider salinity tolerance as adults than either B. liederi or D. longiremis. Although typically considered to 'prefer' freshwater, B. calyciflorus is frequently observed in brackish waters (e.g. Brain et al., 1995; Park \& Marshall, 2000). It is also the only species in these trials that successfully hatched into $8 \%$ salinity during days $0-10$, albeit at rates significantly lower than in freshwater. This finding is consistent with observations of Snell et al. (1991), who reported an approximately $40 \%$ reduction in the hatching rate of $B$. calyciflorus at $8 \%$ as compared with $2 \%$ growth media.

The 'maximum' hatching rates observed at $0 \%$ ranged from 16-89\%. Bailey et al. (2003) suggested that pore water salinity might be negatively correlated with hatching success. Our study also found a low hatching rate for eggs recovered from sediments with a pore water salinity of $20 \%$ or higher ( 16 and $37 \%$ ). However, lower pore water salinity $(\leq 10 \%$ ) did not guarantee a high hatching rate (i.e. $32 \%$ hatch for $4 \%$ ), so other factors (such as age of eggs, duration of diapause or hatching cues) are probably involved. In addition, the effects seen in both studies may be impacted by the wide salinity tolerance of $B$. calyciflorus (i.e. $10 \%$ is only slightly above the natural range for this species, resulting in a high hatching rate at intermediate salinity). Alternatively, pore water salinity measured at the time of collection may not be a good indicator of egg history; eggs may have been retained in ballast sediments for years, experiencing widely varying salinity, of which only the most recent may be reflected by pore water salinity. Nevertheless, while it is possible that the 'maximum' hatching rate (and subsequent reductions in hatching rate) measured in this study may be affected by previous exposures, our results do indicate the effectiveness of ballast water exchange because the sediments carried in transoceanic vessels originate from ports of varying salinity.

Hatching during days 10-20, following transfer to $0 \%$ medium, occurred mainly in the 16 and $32 \%$ treatments. Very little hatching occurred during this period in either the 0 or $8 \%$ treatments, with individuals emerging only from eggs that had not visibly developed during the first 10 days. This suggests that 


\begin{tabular}{llcrc}
\hline \multirow{4}{*}{ Ship } & Organism & \multicolumn{2}{l}{ ANov A effects $[F$ value $($ d.f. $)]$} \\
\cline { 2 - 5 } & \multicolumn{2}{l}{ Treatment } & Time & Time $\times$ treatment \\
\hline 1 (FP) & Bosmina liederi & $32.56(3,16)^{* * *}$ & $43.48(3,48)^{* * *}$ & $16.98(9,48)^{* * *}$ \\
2 (DB) & Daphnia longiremis & $368.97(3,16)^{* * *}$ & $353.05(9,144)^{* * *}$ & $350.90(27,144)^{* * *}$ \\
3 (DB) & Brachionus calyciflorus & $19.78(3,17)^{* * *}$ & $41.08(7,119)^{* * *}$ & $10.39(21,119)^{* * *}$ \\
4 (DB) & Brachionus calyciflorus & $36.60(3,16)^{* * *}$ & $47.26(4,64)^{* * *}$ & $15.10(12,64)^{* * *}$ \\
4 (FP) & Brachionus calyciflorus & $6.15(3,16)^{*}$ & $14.97(6,96)^{* * *}$ & $6.54(18,96)^{* * *}$ \\
5 (DB) & Brachionus calyciflorus & $35.25(3,16)^{* * *}$ & $322.04(4,64)^{* * *}$ & $22.47(12,64)^{* * *}$ \\
\hline
\end{tabular}

Table 2 Analysis of variance with repeated measures demonstrating the effect of salinity treatment on the hatching rate of diapausing eggs

Data were arcsine square root transformed prior to analysis. Significance levels for

$F$-values: ${ }^{*} P<0.05 ;{ }^{* * *} P<0.0001$. Ship tanks are identified by type: $\mathrm{FP}$, forepeak tank;

DB, double-bottom tank.

the Bosmina and Daphnia eye-stage embryos that developed by day 5 at $8 \%$ were no longer viable. It is possible that a salinity of $8 \%$ is sufficiently low for the initiation of egg development in freshwater species, but too high for complete development and emergence to occur. In contrast, no development in these genera was apparent in eggs exposed to $32 \%$ water, thus there remained a 'bank' of viable embryos left to emerge following transfer to freshwater media. Although both B. liederi and D. longiremis displayed this trend, we cannot explain why only Daphnia eggs hatched after exposure to $32 \%$. However, this trend was also observed for B. calyciflorus, with a higher emergence rate after exposure to higher rather than to lower salinity during the latter half of the experiment, particularly for eggs from ship 5. A similar phenomenon was observed by Lutz, Marcus \& Chanton (1994), who exposed copepod resting eggs to variable oxygen conditions. They noted that low oxygen concentrations were more detrimental to egg viability than total anoxia because metabolism was completely shut down during anoxia but not under low oxygen conditions. Thus, there appears to be greater interaction between the embryo and the environment under nearly favourable conditions than under extreme conditions. However, it is also possible that the transfer of eggs from 32 to $0 \%$ acted as a stronger hatching cue than the transfer of eggs from 8 or 16 to $0 \%$. If this is the case, then subjecting diapause eggs to ballast water of $32 \%$ may actually promote mass hatching once the eggs are returned to freshwater conditions.

Charmantier \& Charmantier-Daures (2001) suggested that rehydrated Artemia embryos are protected from high salinity by the cyst envelope that is permeable to water but impermeable to ions. How- ever, salinity and temperature are known to interact in their effects on tolerance, with temperature affecting metabolic rate, ion uptake rate, and membrane permeability (Lee \& Bell, 1999). Our experiments explored salinity tolerance at $20{ }^{\circ} \mathrm{C}$, arguably a more challenging environment than exposure at a lower temperature for temperate species. It will be necessary to conduct future trials at a variety of temperatures to deduce the interaction between temperature and salinity on diapausing egg viability.

The variation in hatching rate seen among $B$. calyciflorus trials after exposure (day 10-20) may have resulted from the disparate histories of the populations tested, as indicated by pore water salinity of ballast sediments. Of particular interest was the hatching rate of B. calyciflorus collected from ship 5, as $78 \%$ eggs hatched successfully after exposure to salinities up to open-ocean levels (i.e. $32 \%$ ). In contrast, hatching rates of the other three B. calyciflorus populations were significantly reduced after similar exposure $(<10 \%)$. It is possible that salinity experienced during diapause egg formation may influence the range of salinities eggs can survive while dormant, much like it affects the optimal salinity for the initiation of hatching for the euryhaline rotifer Brachionus plicatilis Müller (Gilbert, 1974). We were unable to explore this hypothesis, as the origins of the diapausing eggs in this study are unknown. Future studies using clonal populations from both permanent and temporary habitats may help clarify this possibility.

In general, $<10 \%$ of Daphnia and Brachionus eggs hatched after salinity exposure in our experiments. Nevertheless, considering the high egg density in ballast sediments $\left(10^{4}-10^{5}\right.$ eggs $\mathrm{m}^{-2}$ using $1.6 \mathrm{~g} \mathrm{~cm}^{-3}$ 
conversion factor for wet sediment), large populations of viable zooplankton eggs may remain after salinity exposure. While it is possible that a longer exposure may have reduced egg viability further, the length of transoceanic crossings will generally not permit longer exposure regimes. As only a small 'seed population' is necessary to establish a cohort of reproductive individuals, and given that the maximum density of diapausing eggs in natural populations ranges between $10^{3}$ and $10^{6}{\text { eggs } \mathrm{m}^{-2}}^{-2}$ (Hairston, 1996), new populations could establish when salinity returns to favourable values (i.e. when the vessel subsequently loads freshwater, or if the eggs get flushed into a freshwater environment). Hall \& Burns (2001) suggest that resting eggs of Boeckella hamata Brehm, a freshwater copepod, are responsible for the recolonisation of the tidallyinfluenced Lake Waihola, New Zealand, after seasonal salinisation up to $4.8 \%$. The average hatching rate for resting eggs of $B$. hamata was only $2.3 \%$ under optimal conditions in the laboratory. Therefore, while ballast water exchange may reduce the viability of diapausing eggs by as much as $90 \%$ for some taxa, it apparently does not offer complete protection against non-indigenous species entering the Great Lakes by this mechanism. Interestingly, our study indicates that ballast water exchange using brackish water (e.g. $8 \%$ ) may have a larger impact on diapausing egg viability than $32 \%$; however, this effect would have to be weighed against the possibility of introducing live euryhaline species in water of lower salinity, for which ballast water exchange of $32 \%$ is decidedly more effective (Locke et al., 1993; MacIsaac et al., 2002).

Furthermore, most transoceanic vessels currently trading on the Great Lakes declare 'no ballast on board' status (Colautti et al., 2003), and thus are exempt from ballast water exchange regulations (United States Coast Guard, 1993). MacIsaac et al. (2002) suggested that these vessels, collectively, may pose a higher invasion risk than vessels entering the system with saline ballast water owing to the abundance of viable diapausing eggs contained within residual sediments. Our results suggest that the risk posed by diapausing eggs present in sediments of these vessels could be reduced, but not eliminated, by introducing a lens of saltwater into the 'empty' ballast tanks similar to ballast exchange.
Sala et al. (2000) suggested that lakes will experience very steep declines in biodiversity this century owing to biotic exchange, land use change and climate change. The salinity of endorheic freshwater habitats is likely to increase during summer months as water inputs decline and evaporation increases (Schindler, 1997, 2001). In addition, coastal lakes and freshwater habitats upstream from tidal estuaries may suffer periodic salinisation as pulsing surges of saltwater seep inland owing to evaporation and anthropogenic diversion of freshwater (Jones, 1994; Hall \& Burns, 2003). The persistence of populations through salinity fluctuations by means of diapausing eggs could have profound implications on the extent of biodiversity loss during habitat change. Species incapable of tolerating changing salinity could be replaced by taxa tolerant of brackish or saline conditions (Schindler, 1997); however, this study demonstrates that some populations may be capable of tolerating enhanced fluctuations in habitat salinity, providing a mechanism for enriching biodiversity if the habitat returns to freshwater conditions.

\section{Acknowledgments}

We are grateful to F. Dobbs for providing pore water salinity data, and D. Gray for laboratory assistance. The Shipping Federation of Canada, the Great Lakes Shipping Association, and their ship agents, masters, officers and crew were all very accommodating to our needs. This project was supported by an NSERC Industrial Postgraduate Scholarship, in partnership with the Shipping Federation of Canada, an Ontario Graduate Scholarship and an Ontario Federation of Anglers and Hunters Conservation Grant to SAB, and by a Premier's Research Excellence Award to HJM. This work was conducted under the multi-institutional Great Lakes NOBOB Project funded by the Great Lakes Protection Fund, the National Oceanic and Atmospheric Administration (NOAA), the U.S. Environmental Protection Agency, and the U.S. Coast Guard. The project was co-managed by the Cooperative Institute for Limnology and Ecosystems Research and the NOAA Great Lakes Environmental Research Laboratory and sponsored under cooperative agreement NA17RJ1225 from the Office of Oceanic and Atmospheric Research, NOAA (GLERL Contribution 1293). 


\section{References}

Bailey S.A., Duggan I.C., van Overdijk C.D.A., Jenkins P.T. \& MacIsaac H.J. (2003) Viability of invertebrate diapausing eggs collected from residual ballast sediment. Limnology and Oceanography, 48, 1701-1710.

Brain C.K., Fourie I. \& Shiel R.J. (1995) Rotifers of the Kalahari Gemsbok National Park, South Africa. Hydrobiologia, 313/314, 319-324.

Burgess R. (2001) An improved protocol for separating meiofauna from sediments using colloidal silica sols. Marine Ecology Progress Series, 214, 161-165.

Charmantier G. \& Charmantier-Daures M. (2001) Ontogeny of osmoregulation in Crustaceans: The embryonic phase. American Zoologist, 41, 1078-1089.

Colautti R.I., Niimi A.J., van Overdijk C.D.A., Mills E.L., Holeck K. \& MacIsaac H.J. (2003) Spatial and temporal analysis of transoceanic shipping vectors to the Great Lakes. In: Invasion Pathways: Analysis of Invasion Patterns and Pathway Management. (Eds G.M. Ruiz, J.T. Carlton \& R.N. Mack ), pp. 227-246. Island Press, Washington, D.C.

Costello C.J. \& Solow A.R. (2003) On the pattern of discovery of introduced species. Proceedings of the National Academy of Sciences USA, 100, 3321-3323.

Frey D.G. (1993) The penetration of cladocerans into saline waters. Hydrobiologia, 267, 233-248.

Gilbert J.J. (1974) Dormancy in rotifers. Transactions of the American Microscopical Society, 93, 490-513.

Grice G.D. \& Marcus N.H. (1981) Dormant eggs of marine copepods. Oceanography and Marine Biology Annual Review, 19, 125-140.

Grigorovich I.A., Colautti R.I., Mills E.L., Holeck K. \& MacIsaac H.J. (2003) Ballast-mediated animal introductions in the Laurentian Great Lakes: retrospective and prospective analyses. Canadian Journal of Fisheries and Aquatic Sciences, 60, 740-756.

Hairston N.G. Jr (1996) Zooplankton egg banks as biotic reservoirs in changing environments. Limnology and Oceanography, 41, 1087-1092.

Hairston N.G. Jr \& Cáceres C.E. (1996) Distribution of crustacean diapause: Micro- and macroevolutionary pattern and process. Hydrobiologia, 320, 27-44.

Hall C.J. \& Burns C.W. (2001) Hatching of Boeckella hamata (Copepoda: Calanoida) resting eggs from sediments of a tidally influenced lake. New Zealand Journal of Marine and Freshwater Research, 35, 235-238.

Hall C.J. \& Burns C.W. (2002) Mortality and growth responses of Daphnia carinata to increases in temperature and salinity. Freshwater Biology, 47, 451-458.

Hall C.J. \& Burns C.W. (2003) Responses of crustacean zooplankton to seasonal and tidal salinity changes in the coastal Lake Waihola, New Zealand. New Zealand Journal of Marine and Freshwater Research, 37, 31-43.

Hebert P.D.N. \& Crease T.J. (1980) Clonal existence in Daphnia pulex (Leydig): another planktonic paradox. Science, 207, 1363-1365.

Jones G. (1994) Global warming, sea level change and impact on estuaries. Marine Pollution Bulletin, 28, 7-14.

Lee C.E. \& Bell M.A. (1999) Causes and consequences of recent freshwater invasions by saltwater animals. Trends in Ecology and Evolution, 14, 284-288.

Locke A., Reid D.M., van Leeuwen H.C., Sprules W.G. \& Carlton J.T. (1993) Ballast water exchange as a means of controlling dispersal of freshwater organisms by ships. Canadian Journal of Fisheries and Aquatic Sciences, 50, 2086-2093.

Lutz R.V., Marcus N.H. \& Chanton J.P. (1994) Hatching and viability of copepod eggs at two stages of embryological development: anoxic/hypoxic effect. Marine Biology, 119, 199-204.

MacIsaac H.J., Robbins T.C. \& Lewis M.A. (2002) Modeling ships' ballast water as invasion threats to the Great Lakes. Canadian Journal of Fisheries and Aquatic Sciences, 59, 1245-1256.

Miracle M.R. \& Serra M. (1989) Salinity and temperature influence in rotifer life history characteristics. Hydrobiologia, 186/187, 81-102.

Park G.S. \& Marshall H.G. (2000) The trophic contributions of rotifers in tidal freshwater and estuarine habitats. Estuarine, Coastal and Shelf Science, 51, 729-742.

Reid D.F. \& Orlova M.I. (2002) Geological and evolutionary underpinnings for the success of PontoCaspian species invasions in the Baltic Sea and North American Great Lakes. Canadian Journal of Fisheries and Aquatic Sciences, 59, 1144-1158.

Ricciardi A. (2001) Facilitative interactions among aquatic invaders: is an 'invasional meltdown' occurring in the Great Lakes? Canadian Journal of Fisheries and Aquatic Sciences, 58, 2513-2525.

Ricciardi A. \& MacIsaac H.J. (2000) Recent mass invasion of the North American Great Lakes by Ponto-Caspian species. Trends in Ecology and Evolution, 15, 62-65.

Rigby G.R., Hallegraeff G.M. \& Sutton C. (1999) Novel ballast water heating technique offers cost-effective treatment to reduce the risk of global transport of harmful marine organisms. Marine Ecology Progress Series, 191, 289-293.

Ruiz G.M., Rawlings T.K., Dobbs F.C., Drake L.A., Mullady T., Huq A. \& Colwell R.R. (2000) Global spread of microorganisms by ships. Nature, 408, 49-50.

Sala O.E., Chapin F.S. III, Armesto J.J. et al. (2000) Global biodiversity scenarios for the year 2100 . Science, 287, 1770-1774. 
Schindler D.W. (1997) Widespread effects of climatic warming on freshwater ecosystems in North America. Hydrological Processes, 11, 1043-1067.

Schindler D.W. (2001) The cumulative effects of climate warming and other human stresses on Canadian freshwaters in the new millennium. Canadian Journal of Fisheries and Aquatic Sciences, 58, 18-29.

Schwartz S.S. \& Hebert P.D.N. (1987) Methods for the activation of the resting eggs of Daphnia. Freshwater Biology, 17, 373-379.

Snell T.W., Moffat B.D., Janssen C. \& Persoone G. (1991) Acute toxicity tests using rotifers. IV. Effects of cyst age, temperature and salinity on the sensitivity of Brachionus calyciflorus. Ecotoxicology and Environmental Safety, 21, 308-317.
Teschner M. (1995) Effects of salinity on the life history and fitness of Daphnia magna: variability within and between populations. Hydrobiologia, 307, 33-41.

United States Coast Guard. (1993) Ballast water management for vessels entering the Great Lakes. Code of Federal Regulations 33-CFR Part 151.1510.

Williams D.D. (1998) The role of dormancy in the evolution and structure of temporary water invertebrate communities. Archiv für Hydrobiologie, Special Issues in Advanced Limnology, 52, 109-124.

(Manuscript accepted 28 December 2003) 